\title{
Kerangka Kerja Pelatihan Cybersecurity Untuk Siswa Sekolah Menengah Pertama dan Atas (SMP-SMA)
}

\section{Cybersecurity Training Framework for Junior and Senior High School Students}

\author{
Agung Prabowo ${ }^{1}$, Rommi Kaestria ${ }^{2}$, Ika Safitri Windiarti ${ }^{3}$, Sulistyowati ${ }^{4}$ \\ ${ }^{1,2}$ Program Studi Sistem Informasi, STMIK Palangka Raya , Jalan G. Obos, No. 114, Palangka Raya \\ ${ }^{3}$ Program Studi Ilmu Komputer, Universitas Muhammadiyah Palangkaraya, Jalan RTA Milono Km 1,5, \\ Palangka Raya \\ ${ }^{4}$ Program Studi Teknik Informatika, STMIK Palangka Raya, Jalan G. Obos, No. 114, Palangka Raya \\ Email: agungdosen@gmail.com
}

\begin{abstract}
ABSTRAK
Semua remaja usia SMP - SMA harus memiliki pengetahuan tentang cybersecurity yaitu tingkat keamanan dalam menggunakan teknologi Internet baik melalui PC maupun perangkat mobile lainnya. Cybersecurity adalah upaya untuk melindungi informasi dari adanya cyber attack, yaitu semua jenis tindakan untuk mengganggu kerahasiaan (confidentiality), integritas (integrity), dan ketersedian (availability) informasi secara sengaja. Tujuan dari penelitian ini adalah untuk menemukan kerangka kerja yang tepat dalam memberikan pelatihan kepada siswa SMP dan SMA tentang cybersecurity, yang nantinya setelah dianalisis dan disusun kerangkanya, akan muncul adanya program pelatihan cybersecurity. Program tersebut dikhususkan berkonsentrasi pada keamanan identitas baik secara pribadi, keluarga maupun institusi. Metode penelitian ini adalah mix methods antara survey kualitatif dan kuantitatif. Penelitian ini akan diadakan dengan cara melakukan survey dan uji coba pelatihan kepada siswa SMP dan SMA di Palangka Raya tentang penggunaan internet yang meliputi fasilitas email, social media, dan platform digital lainnya dengan memperhatikan aspek keamanan informasi dan data pribadi. Output dari penelitian ini adalah kerangka pelatihan cybersecurity awareness sebagai bahan pelengkap dalam kurikulum dalam pendidikan SMP dan SMA.
\end{abstract}

Kata kunci: cybersecurity, keamanan, pelatihan, siswa SMP, siswa SMA

\section{ABSTRACT}

Teenagers who are junior and senior high school students should have knowledge of cybersecurity, including the level of security in using Internet technology either through PCs or other mobile device. Cybersecurity is an effort to protect information from cyber attacks. Cyber attacks are all types of actions to disrupt the confidentiality, integrity, and availability of information intentionally. The purpose of this research is to find the right framework in providing training to junior and senior high school students on cybersecurity, which later after being analyzed and structured, a cybersecurity training will appear. The program is devoted to concentrating on identity security both personally, family and institutionally. This research method is a mix of qualitative and quantitative survey methods. This research will be conducted by conducting surveys and training trials for junior and senior high school students in Palangka Raya on internet use which includes email facilities, social media, and other digital platforms by taking into the account the secirity aspects of information and personal data. The output of this research is a cybersecurity awareness training framework as a complementary material in the curriculum in junior and senior high school education.

Keywords: cybersecurity, security, training, junior highschool students, senior highschool students

\section{PENDAHULUAN}

Dalam kehidupan sehari-hari banyak individu, organisasi dan negara-negara yang sangat bergantung dalam menjalankan aktifitasnya kepada jaringan internet (Pandita, 2017). Hari ini, dengan adanya internet membuat dunia saling terhubung sehingga seseorang dari wilayah yang berbeda dan dengan zona waktu yang berbeda dapat saling bekerja, berkolaborasi dalam melakukan pekerjaanya dengan cara terhubung ke internet (Manoharan, et.el., 2020). Bahkan pemerintahan pun menjalankan operasinya beralih dengan menggunakan jalur internet sehingga terbentuk yang kita 


$$
\begin{aligned}
& \text { Agung Prabowo, Rommi Kaestria \& Ika Safitri Windiarti, Kerangka Kerja Pelatihan Cybersecurity } \\
& \text { Untuk Siswa Sekolah Menengah Pertama Dan Atas (SMP-SMA) }
\end{aligned}
$$

sebut dengan e-government (Umanailo, et.el., 2019). Namun demikian, meskipun dunia maya menawarkan berbagai macam kemudahan dan kesempatan yang banyak tapi juga disertai dengan banyak risiko, yang tidak disadari oleh banyak pengguna Internet (Shahin, 2017). Orang-orang yang menggunakan Wi-Fi di tempat umum untuk keperluan bisnis atau keperluan pribadi lainya maka data-data organisasi atau data-data perusahaan bahkan data-data pribadi yang diproses melalui jaringan tersebut menjadi tidak terlindungi (Btoush, et.al., 2011). Bisa jadi karena kelalaian karyawan tersebut bisa menjadi jalan bagi para pelaku kejahatan cyber untuk melakukan hal-hal yang membahayakan organisasi atau perusahaan tempat dia bekerja melalui jaringan internet (Persadha, 2016). Dengan demikian, berbagai negara telah mengembangkan dan menerapkan kesadaran keamanan cyber dan langkah-langkah untuk mendidik agar bisa melawan ketidak pedulian tentang pentingnya keamanan dalam beraktifitas menggunakan Internet (Tayibnapis, 2018).

Masalah yang diidentifikasi dalam penelitian ini adalah bahwa siswa SMP dan SMA khususnya di Palangkaraya kurang memahami dan peduli tentang bahayanya internet. Hal ini terjadi ketika mereka mengakses email, social media maupun platform digital. Oleh karena itu perlu ditemukan kerangka kerja pelatihan cybersecurity.

Sesuai dengan identifikasi masalah, rumusan masalah penelitian ini adalah:

1. Seberapa penting siswa dilatih tentang bahaya pencurian identitas di internet?

2. Bagaimana metode yang tepat dalam pengajaran cybersecurity di sekolah?

Penelitian ini memiliki pembatasan masalah yaitu untuk Menyusun metode pelatihan berdasarkan pengamatan terhadap pengalaman dan pengetahuan siswa SMP dan SMA di Palangka Raya tentang aktivitas mereka di dunia maya di penelitian sebelumnya. Aktivitas didunia maya ini meliputi akses email, social media seperti Facebook, twitter, Instagram, dan yang lain.

Tujuan dari penelitian ini adalah untuk menemukan kerangka kerja yang tepat dalam memberikan pelatihan kepada siswa SMP dan SMA tentang cybersecurity, yang nantinya setelah dianalisis dan disusun kerangkanya, akan muncul adanya program pelatihan cybersecurity. Program tersebut dikhususkan berkonsentrasi pada keamanan identitas baik secara pribadi, keluarga maupun institusi.

\section{TINJAUAN PUSTAKA}

Indonesia merupakan salah satu negara dengan penduduk terbanyak di dunia. Indonesia berada di peringkat 4 dengan total $273,523,615$ penduduk berada di bawah
Amerika Serikat, India dan Tiongkok (Broadhurst and Chang, 2013). Didukung dengan semakin luasnya jangkauan layanan internet, serta murahnya harga perangkat pendukung penggunaan internet seperti smartphone, personal computer, tablet, laptop dan lain sebagainya membuat pengguna perangkat Teknologi Informasi tumbuh pesat di Indonesia (Saputra, 2016).

Seiring pengguna internet indonesia yang makin besar maka Jumlah kejahatan dunia maya di Indonesia menjadi tertinggi ke dua di dunia setelah Jepang. Total serangan cyber ini ada 90 juta menurut Badan Pengkajian dan Penerapan Teknologi (BPPT) (Wisnumurti et.al., 2018).

Ini menunjukan bahwa indonesia menjadi negara dengan beresiko tinggi dalam hal serangan kejahatan di dunia maya dan tingkat kesadaran yang rendah dari penduduknya akan hal pentingnya peduli dengan keamanan dalam beraktifitas di dunia maya.

Maka sangatlah penting untuk meningkatkan kepedulian tentang bagaimana menggunakan internet secara aman terutama di kalangan orang-orang berusia muda di indonesia. sebagaimana kita ketahui secara demografi jumlah penduduk indonesia berusia muda lebih dominan, oleh sebab itu indonesia sering disebut mempunyai faktor pertumbuhan ekonomi yang penting yaitu bonus demografi.

Selama ini pengenalan tentang cyber security dalam menggunakan internet banyak hanya diadakan di kalangan kalangan pemuda atau yang berusia lebih tua akan tetapi Bagi kalangan remaja terutama yang di bangku sekolah sangat jarang untuk mendapatkan pengetahuan tentang cyber security oleh karenanya kesadaran di kalangan mereka masih sangat rendah akan pentingnya hal ini.

\section{METODE PENELITIAN}

Penelitian ini menggunakan metode training design untuk para siswa SMP dan SMA Palangkaraya. Ini adalah salah satu jenis penelitian di bidang informatika (Windiarti, 2021). Tujuan dari training design ini yang pertama adalah untuk memberikan training yang mudah dimengerti oleh siswa berdasarkan pengetahuan dan pengalaman dari para siswa SMP dan SMA di Palangkaraya pada penelitian sebelumnya. Tujuan kedua adalah untuk menemukan metode yang tepat sehingga dapat diimplementasikan di sekolah-sekolah.

Proses pengumpulan literature review dimulai dengan pengambilan pustaka yang relevan diikuti oleh sketsa design training. Proses ini dijelaskan secara rinci di bawah ini.

1. Pengambilan Pustaka; Pustaka yang relevan untuk digunakan sebagai acuan training design dikumpulkan 
dan dianalisis berdasarkan pengalaman dan pengetahuan dari siswa SMP dan SMA di Palangka Raya pada penelitian sebelumnya. Proses pengambilan Pustaka ini mengidentifikasi sejumlah metode training yang sesuai dengan semua kriteria kelayakan. Target jumlah pustaka penelitian adalah 60 jurnal internasional dan nasional.

2. Fase Analisis Pustaka; Dalam Penelitian ini, setelah kami melakukan tinjauan pustaka dan menyusun kerangka pelatihan. Proses ini dilakukan pada bulan April-Mei 2021.

3. Proses pengembangan metode akan dilakukan dengan mengujicoba metode training yang ditemukan, pada beberapa sampel sekolah.

\section{IMPLEMENTASI DAN PEMBAHASAN}

Pembahasan pada penelitian ini dimulai dari penentuan perancangan pelatihan pada umumnya.

\subsection{Langkah-langkah Desain Kerangka Pelatihan}

Dalam mendisain kerangka pelatihan diperlukan Langkah-langkah seperti pada Gambar 1.

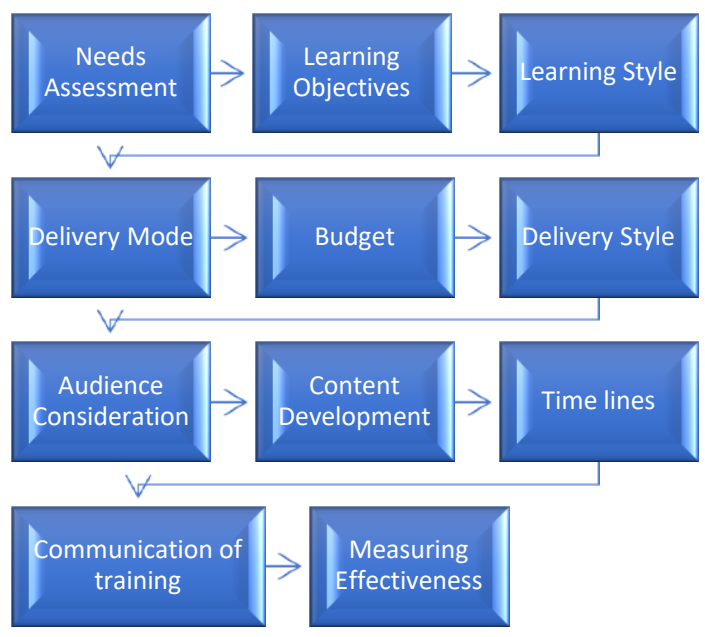

Gambar 1. Langkah-langkah Desain Kerangka Pelatihan

Pertimbangan untuk mengembangkan program pelatihan adalah sebagai berikut:

a) Needs Assessment (Penilaian kebutuhan)

Langkah pertama dalam mengembangkan program pelatihan adalah menentukan apa yang dibutuhkan organisasi dalam hal pelatihan. Ada tiga tingkat penilaian kebutuhan pelatihan:

1. Penilaian organisasi. Disini kita dapat menentukan keterampilan, pengetahuan, dan kemampuan yang dibutuhkan perusahaan untuk memenuhi tujuan strategisnya.
2. Penilaian pekerjaan (tugas). Jenis penilaian ini melihat tugas spesifik, pengetahuan keterampilan, dan kemampuan yang dibutuhkan untuk melakukan pekerjaan dalam organisasi.

3. Penilaian individu. Penilaian individu melihat kinerja seorang karyawan individu dan menentukan pelatihan apa yang harus dicapai untuk individu tersebut.

b) Tujuan pembelajaran

Tujuan pembelajaran adalah apa yang diinginkan dari peserta untuk dapat melakukan, menjelaskan, atau menunjukkan pada akhir pelatihan. Tujuan pembelajaran yang baik adalah berbasis kinerja dan jelas, dan hasil akhir dari tujuan pembelajaran dapat diamati atau diukur dengan cara tertentu.

c) Gaya belajar

Memahami gaya belajar merupakan komponen penting untuk setiap program pelatihan. Trainer yang efektif mencoba mengembangkan pelatihan untuk memenuhi tiga gaya belajar yang berbeda:

1. Pembelajar visual. Seorang pembelajar visual paling baik dicapai dengan menggunakan grafik, gambar, dan gambar.

2. Pembelajar auditori. Seorang pembelajar auditori belajar dengan suara. Pembelajar auditori akan belajar dengan mendengarkan ceramah.

3. Pembelajar kinestetik. Seorang pembelajar kinestetik belajar dengan mengembangkan perasaan terhadap suatu pengalaman. Tipe pembelajar ini cenderung belajar dengan melakukan daripada mendengarkan atau melihat orang lain melakukannya.

Kebanyakan individu menggunakan lebih dari satu jenis gaya belajar, tergantung pada jenis informasi yang mereka proses.

d) Mode penyampaian

Tergantung pada jenis pelatihan yang perlu disampaikan, Anda mungkin akan memilih mode yang berbeda untuk menyampaikan pelatihan. Saat memilih mode penyampaian, penting untuk mempertimbangkan audiens dan batasan anggaran. Jenis-jenis pelatihan yang disarankan, menurut mode penyampaiannya seperti pada Tabel 1.

e) Anggaran

Jenis pelatihan yang dilakukan akan sangat bergantung pada anggaran. Sebuah rencana anggaran harus dikembangkan yang mencantumkan biaya sebenarnya untuk biaya yang diperlukan dalam pelatihan.

\section{f) Gaya Penyampaian}

Penting juga untuk diingat bahwa kebanyakan orang tidak belajar hanya melalui "PowerPoint"; mereka belajar dalam berbagai cara, seperti pendengaran, kinestetik, atau visual. Jenis ice-breaking, diskusi singkat, dan kegiatan 
apa yang dapat Anda gabungkan untuk membuat pelatihan seinteraktif mungkin? Banyak trainer menerapkan video online, podcast, dan media interaktif lainnya dalam sesi pelatihan mereka. Hal ini membuat pelatihan lebih menarik.

g) Audiens/ Hadirin

Sudah berapa lama mereka bekerja di organisasi, atau apakah mereka peserta baru? Di departemen apa mereka bekerja? Jawaban atas pertanyaan-pertanyaan ini dapat membantu Anda mengembangkan gaya penyampaian yang relevan untuk hasil pelatihan yang lebih baik.

\section{h) Pengembangan Konten}

Konten yang ingin Anda sampaikan mungkin merupakan salah satu bagian terpenting dalam pelatihan dan salah satu yang paling memakan waktu untuk dikembangkan.

Pengembangan konten diawali dengan pengembangan tujuan pembelajaran dan kemudian garis besar topik utama yang ingin dibahas. Kemudian dapat mengembangkan modul atau slide PowerPoint, aktivitas, pertanyaan diskusi, dan teknik pembelajaran lainnya.

Tabel 1 Jenis Pelatihan dan Penyampaian

\begin{tabular}{|c|c|}
\hline $\begin{array}{l}\text { Metode } \\
\text { Penyampaian }\end{array}$ & Jenis Pelatihan yang Disarankan \\
\hline $\begin{array}{l}\text { On-the-job } \\
\text { coaching }\end{array}$ & $\begin{array}{l}\text { - Pelatihan teknis } \\
\text { - Pelatihan keterampilan } \\
\text { - Pelatihan manajerial } \\
\text { - Pelatihan keselamatan }\end{array}$ \\
\hline Mentor & $\begin{array}{l}\text { - Pelatihan teknis } \\
\text { - Pelatihan keterampilan } \\
\text { - Pelatihan manajerial } \\
\text { - Pelatihan keselamatan }\end{array}$ \\
\hline $\begin{array}{l}\text { Brown bag } \\
\text { lunch }\end{array}$ & $\begin{array}{l}\text { - Pelatihan berkualitas } \\
\text { - Pelatihan softskill } \\
\text { - Pelatihan professional } \\
\text { - Pelatihan tim } \\
\text { - Pelatihan keselamatan }\end{array}$ \\
\hline Web-based & $\begin{array}{l}\text { - Pelatihan teknis } \\
\text { - Pelatihan berkualitas } \\
\text { - Pelatihan keterampilan } \\
\text { - Pelatihan soft skill } \\
\text { - Pelatihan professional } \\
\text { - Pelatihan tim } \\
\text { - Pelatihan manajerial } \\
\text { - Pelatihan keselamatan }\end{array}$ \\
\hline Job shadowing & $\begin{array}{l}\text { - Pelatihan teknis } \\
\text { - Pelatihan berkualitas } \\
\text { - Pelatihan keterampilan } \\
\text { - Pelatihan keselamatan }\end{array}$ \\
\hline
\end{tabular}

\begin{tabular}{|c|c|}
\hline $\begin{array}{l}\text { Metode } \\
\text { Penyampaian }\end{array}$ & Jenis Pelatihan yang Disarankan \\
\hline Job swapping & $\begin{array}{l}\text { - Pelatihan teknis } \\
\text { - Pelatihan berkualitas } \\
\text { - Pelatihan keterampilan } \\
\text { - Pelatihan professional } \\
\text { - Pelatihan tim } \\
\text { - Pelatihan manajerial } \\
\text { - Pelatihan keselamatan }\end{array}$ \\
\hline $\begin{array}{l}\text { Vestibule } \\
\text { training }\end{array}$ & $\begin{array}{l}\text { - Pelatihan teknis } \\
\text { - Pelatihan berkualitas } \\
\text { - Pelatihan keterampilan } \\
\text { - Pelatihan professional } \\
\text { - Pelatihan tim } \\
\text { - Pelatihan manajerial } \\
\text { - Pelatihan keselamatan }\end{array}$ \\
\hline
\end{tabular}

i) Timelines

Perlu direncanakan berapa banyak waktu yang akan butuhkan untuk memberikan pelatihan. Mungkin satu jam sudah cukup, tetapi terkadang pelatihan bisa memakan waktu sehari atau bahkan seminggu. Setelah mengembangkan konten pelatihan dapat dirancang berapa lama waktu yang dibutuhkan untuk menyampaikannya. Pertimbangkan fakta bahwa kebanyakan orang tidak memiliki banyak waktu untuk pelatihan dan jaga agar waktu pelatihan tetap realistis dan ringkas.

j) Komunikasi

Setelah Anda mengembangkan pelatihan, pertimbangan berikutnya adalah bagaimana Anda akan mengkomunikasikan pelatihan yang tersedia kepada peserta. Pertimbangkan untuk menggunakan intranet, email, dan bahkan poster untuk mengomunikasikan pelatihan.

k) Mengukur Efektivitas

Setelah menyelesaikan pelatihan, kita ingin memastikan tujuan pelatihan kita terpenuhi. Salah satu model untuk mengukur efektivitas pelatihan adalah model Kirkpatrick (Kirkpatrick, 2006), yang dikembangkan pada 1950an. Modelnya memiliki empat level:

1. Reaksi: Bagaimana reaksi peserta terhadap program pelatihan?

2. Pembelajaran: Sejauh mana peserta meningkatkan pengetahuan dan keterampilan?

3. Perilaku: Apakah perilaku berubah sebagai hasil dari pelatihan?

Hasil: Apa manfaat bagi organisasi yang dihasilkan dari pelatihan?

Seperti bisa terlihat pada Gambar 2. 


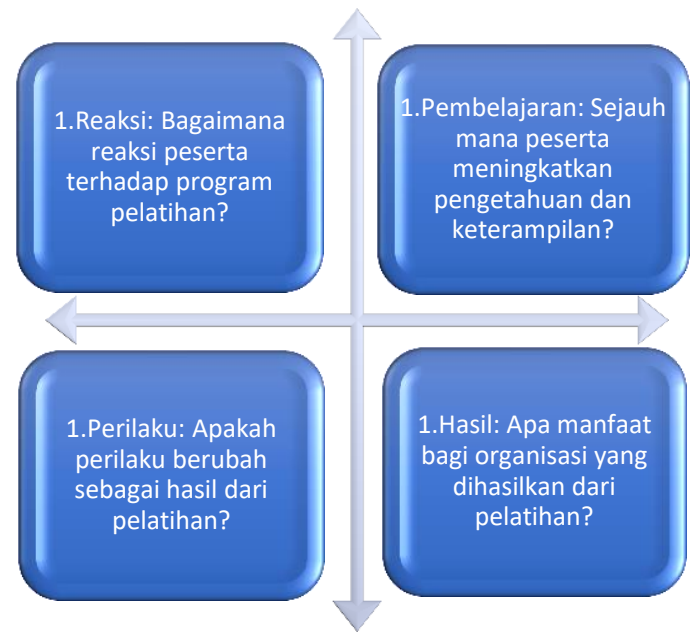

Dalam hal ini, penting untuk kembali meninjau tujuan pembelajaran dan isi pelatihan Anda untuk memastikannya bisa lebih efektif di masa depan.

Trainer dapat menyusun survey misalnya dengan Google Form. Pilihan lain adalah mengedarkan kuis di akhir pelatihan untuk melihat seberapa baik peserta memahami apa yang Anda coba ajarkan kepada mereka. Kuis harus dikembangkan berdasarkan tujuan pembelajaran yang Anda tetapkan untuk pelatihan. Kuis dapat dikirim melalui email ke setiap peserta. Setelah dilihat tanggapan kuis, lalu dapat memodifikasi pelatihan selanjutnya pada hal-hal membutuhkan perbaikan.

Salah satu cara untuk meningkatkan efektivitas program pelatihan adalah memberikan penghargaan kepada peserta terbaik. Misalnya, jika anggaran memungkinkan bisa saja diberikan kenaikan gaji atau imbalan lain.

Gambar 2. Evaluasi Pelatihan Empat Tingkat Kirkpatrick

\subsection{Desain kerangka pelatihan cybersecurity}

Setelah dilakukan analisa, maka diperoleh kerangka pelatihan cybersecurity, sebagaimana tercantum pada Gambar 3 dan 4. 
Agung Prabowo, Rommi Kaestría \& lka Safitri Windiarti, Kerangka Kerja Pelatihan Cybersecurity 2021 Untuk Siswa Sekolah Menengah Pertama Dan Atas (SMP-SMA)

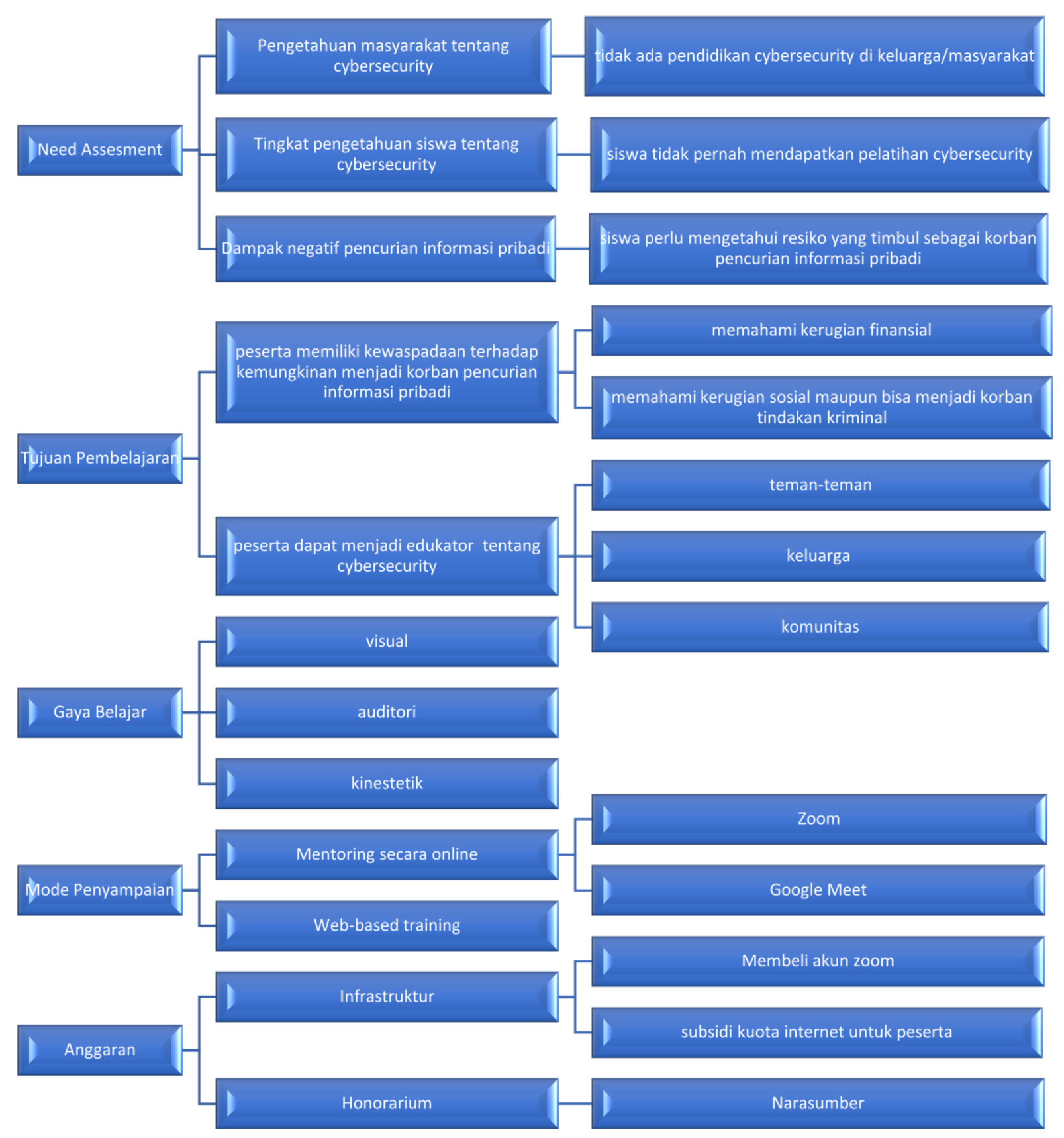

Gambar 3. Desain kerangka pelatihan cybersecurity Bagian 1 


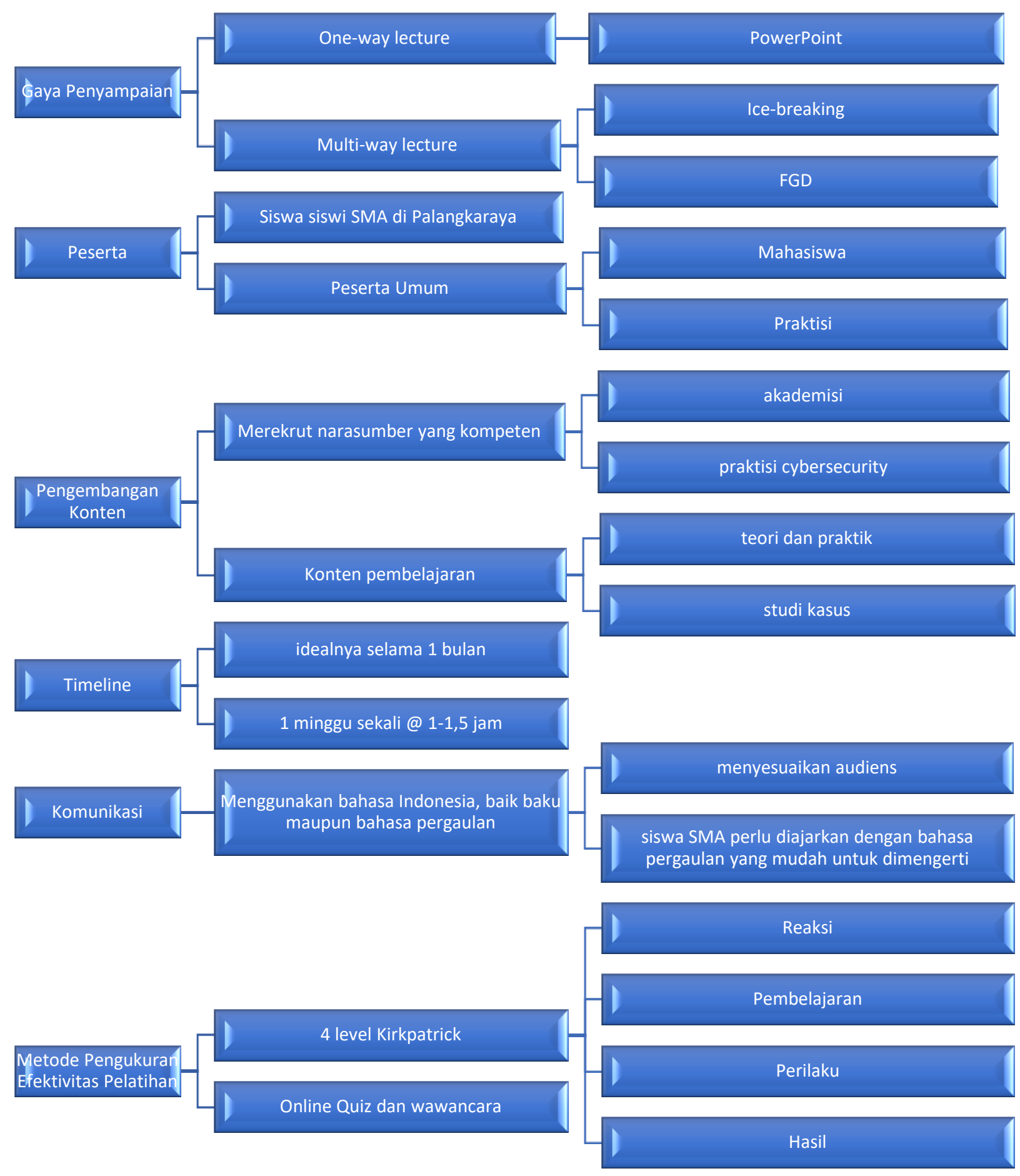

Gambar 4. Desain kerangka pelatihan cybersecurity Bagian 2 
Agung Prabowo, Rommi Kaestría \& lka Safitri Windiarti, Kerangka Kerja Pelatihan Cybersecurity 2021 Untuk Siswa Sekolah Menengah Pertama Dan Atas (SMP-SMA)

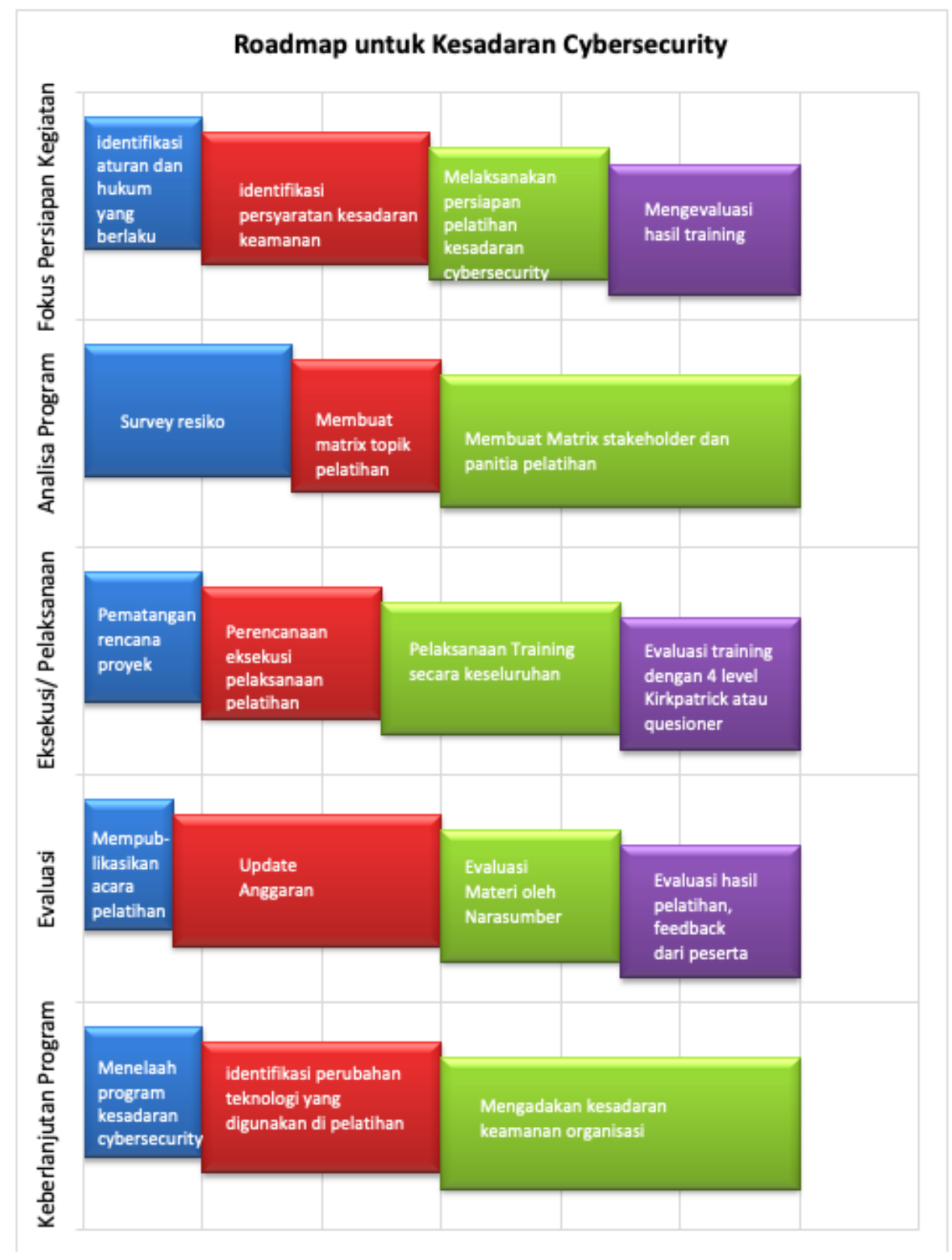

Gambar 5. Roadmap untuk kesadaran Cybersecurity

Pada penelitian ini juga dihasilkan rancangan Roadmap untuk kesadaran Cybersecurity para siswa SMP dan SMA, berupa uraian kegiatan yang dimulai dari persiapan kegiatan, analisa program, eksekusi/pelaksanaan, evaluasi dan diakhiri dengan rencana keberlanjutan program. Hal ini tercantum pada Gambar 5.

Tahap persiapan kegiatan terdiri dari identifikasi aturan hukum yang berlaku, identifikasi persyaratan kesadaran keamanan, melaksanakan persiapan pelatihan, serta mengevaluasi hasil training. Dilanjutkan dengan tahap analisa program dengan adanya survey resiko, membuat matrix topik pelatihan dan membuat matrix stakeholder dan panitian pelatihan. Sedangkan tahapan eksekusi atau pelaksanaan berupa pematangan rencana proyek, perencanaan eksekusi, plekasanaan pelatihan, serta evaluasi dengan bantuan 4 level Kirkpatrick atau kuisioner. 


\begin{tabular}{r|l} 
Jurnal Sains Komputer dan Teknologi Informasi & Page \\
e-issn: 2655-7460. Volume 4 No.1, November 2021 & $72-80$ \\
\hline
\end{tabular}

Tahap Evaluasi yaitu mempublikasikan, update anggaran, evaluasi materi oleh narasumber, serta evaluasi hasil pelatihan dan umpan balik dari peserta. Sedangkan adanya keberlanjutan program akan dilakukan dengan menelaah program ini, kemudian identifikasi teknologi yang digunakan, serta meningkatkan kesadaran cybersecurity dalam ranah organisasi.

\section{KESIMPULAN DAN SARAN}

\subsection{Kesimpulan}

Kesimpulan yang dapat diambil dari penelitian ini adalah sebagai berikut:

1. Fakta yang terjadi di lapangan adalah bahwa rendahnya tingkat pengetahuan siswa SMP- SMA di kota Palangkaraya yaitu terkait cybersecurity dan pentingnya menjaga keamanan data dan informasi pribadi.

2. Penelitian ini juga membahas kesadaran para siswa bahwa mereka berpotensi untuk menjadi korban penipuan di dunia internet. Oleh karena itu perlu dikembangkan suatu kerangka kerja pelatihan cybersecurity.

3. Desain kerangka kerja pelatihan ini didasarkan pada beberapa faktor dan langkah-langkah yang perlu dipertimbangkan. Hal tersebut antara lain needs assesment/penilaian kebutuhan, tujuan pembelajaran, pertimbangan gaya belajar, mode penyampaian, anggaran, gaya penyampaian, peserta, isi/konten, timelines, komunikasi, mengukur efektivitas pelatihan.

4. Pelatihan ini idealnya diberikan dalam kurun waktu 1 bulan dengan durasi 1,5 jam 1 kali dalam seminggu, setara dengan 6 jam secara berkesinambungan

\subsection{Saran}

Pengembangan lebih lanjut dari penelitian ini akan membangun penerapan kurikulum cybersecurity untuk siswa SMA. Beberapa contoh pelatihan keamanan siber menggunakan teknik berbasis permainan dan bermain peran. Kombinasi dan campuran dari kedua teknik tersebut dapat dikembangkan untuk kerangka pelatihan. Tujuannya untuk memberikan pengetahuan dan kesadaran yang cukup kepada mereka agar siap dalam menggunakan teknologi internet.

\section{DAFTAR PUSTAKA}

Pandita, R (2017) "Internet: A Change Agent An Overview Of Internet Penetration \& Growth Across The
World," International Journal Of Information Dissemination And Technology, Vol. 7, No. 2, P. 83, 2017.

Manoharan, A.P., et.al., (2020) "Globalization And Worldwide Best Practices In E-Government," International Journal of Public Administration, Pp. 1-12, 2020.

Umanailo, M. C. B., Et Al., (2019), "Cybercrime Case As Impact Development Of Communication Technology That Troubling Society," Int. J. Sci. Technol. Res, Vol. 8, No. 9, Pp. 1224-1228, 2019.

Shahin, E. (2017), "Is Wifi Worth It: The Hidden Dangers Of Public Wifi," Catholic University Journal Of Law And Technology, Vol. 25, No. 1, P. 7, 2017.

Btoush, M., et.al. (2011), "Increasing Information Security Inside Organizations Through Awareness Learning For Employees," Journal Of Theoretical \& Applied Information Technology, Vol. 24, No. 2, 2011.

Persadha, P. D., et.al. (2016), "How Inter-Organizational Knowledge Sharing Drives National Cyber Security Awareness?: A Case Study In Indonesia," In 2016 18th International Conference On Advanced Communication Technology (Icact), 2016: Ieee, Pp. 550-555.

Tayibnapis, A. Z., et.al, (2018), "The Development Of Digital Economy In Indonesia," Ijmbs International Journal of Management And Business Studies, Vol. 8, No. 3, Pp. 14-18, 2018.

Broadhurst R. and Chang, L. Y., (2013) "Cybercrime In Asia: Trends And Challenges," In Handbook Of Asian Criminology: Springer, 2013, Pp. 49-63.

Saputra, R. W., (2016), "A Survey Of Cyber Crime In Indonesia," In 2016 International Conference On Ict For Smart Society (Iciss), 2016: Ieee, Pp. 1-5.

Wisnumurti, A. A. G. O., et.al., (2018) "Government Policy Of Indonesia To Managing Demographic Bonus And Creating Indonesia Gold In 2045," Journal Of Humanities And Social Science (IosrJhss), Vol. 23, No. 1, Pp. 23-34, 2018.

Prabowo,A., Kaestria, R., and Windiarti, I.S., (2020) "Students' Engagement In Cyber Security Knowledgeability." International Journal Of Advanced Science And Technology, Vol 29 No 04 (2020).

Windiarti, I. S. (2021). Kajian Literatur Trend Penelitian Di Bidang Informatika Dan Komputer Untuk Dosen Dan Mahasiswa. Jurnal Sains Komputer Dan Teknologi Informasi, 3(2), 114-118. https://doi.org/10.33084/jsakti.v3i2.2299 